\title{
COMPARISON OF THE CONTROL METHODS OF ELECTRICAL DRIVES WITH AN ELASTIC COUPLING ALLOWING TO LIMIT THE TORSIONAL TORQUE AMPLITUDE
}

\section{PORÓWNANIE METOD STEROWANIA NAPĘDEM ELEKTRYCZNYM Z POŁĄCZENIEM SPRĘŻYSTYM POZWALAJĄCE NA OGRANICZENIE AMPLITUDY MOMENTU SKRĘTNEGO*}

\begin{abstract}
The article presents some aspects of the speed control of a drive with an elastic coupling which allows to limit the torsional torque amplitude. The limitation of the amplitude of this state variable increases the life of the mechanical couplings of a drive. In the work three regulation systems: PI controller with additional couplings, a cascade control based on the FDC method and MPC (model predictive control) are compared. The subsequent sections present the control system model and describe the discussed control algorithms. Next comprehensive simulation and experimental research is discussed.
\end{abstract}

Keywords: drive with elastic coupling, torsional vibration attenuation.

\begin{abstract}
W artykule przedstawiono zagadnienia zwiq̨ane ze sterowaniem prędkościa napędu z połaczeniem sprężystym, które pozwala na ograniczenie amplitudy momentu skrętnego. Ograniczenie amplitudy tej zmiennej stanu wplywa na wydlużenie żywotności połaczeń mechanicznych napędu. W pracy porównano trzy układy regulacji: regulator PI z dodatkowymi sprzężeniami, kaskadowy regulator bazujacy na metodzie FDC, oraz regulator predykcyjny MPC. W kolejnych rozdziałach przedstawiono model uktadu regulacji, oraz opisano rozpatrywane algorytmy sterowania. Nastepnie przedstawiono wszechstronne badania symulacyjne i eksperymentalne.
\end{abstract}

Stowa kluczowe: napęd z połaczeniem sprężystym, tłumienie drgań skrętnych.

\section{Introduction}

Modern power transmission systems are expected to show higher dynamics while preserving high precision and reliability. Such requirements results in an increasingly higher use of the properties and strength of construction materials. Therefore, in a growing number of drives one can observe finite stiffness of couplings between a drive and machinery. This problem was initially considered in the heavy industry in various types of machines, such as: rolling mills [13], conveyor belts [10] or papermaking machines [20]. However, currently this problem is investigated also in the research on drives for: robots [4], throttling valves [21], wind generators [2] or modern servo drives with magnetic clutches [12].

Various methods are used in the control of vehicle speed or the location of drives with an elastic coupling, starting with simple ones based on a PI controller tuned with account for coupling elasticity [22], to the introduction of additional feedbacks from one to a few state variables to such a controller, a detailed overview of such solutions can be found in [17]. Some other control systems use adaptive control. Such methods as fuzzy sliding mode control and neural control [3,7], as well as vortex control [14] can be distinguished here, this group of methods ensures good oscillation attenuation and it is additionally characterised by high resistance in the case of wrongly determined drive parameters. Another approach to adaptive is presented in $[8,18]$, here a superior system was used to retune controller setting, it continuously reproduces the unknown and variable parameter. Yet another, not so common, is the sliding mode control [9].

In the case drives with an elastic coupling, the major challenge faced by the control system is the attenuation of the oscillation of electro-mechanical state variables. However, another issue which ap- pears in the discussed group of drives is the limitation of the torsional torque amplitude in such a way that the lives of mechanical couplings can be extended, which improves the reliability of the whole drive system. However, the above described methods do not allow to introduce the restriction of the values of state variables (torsional torque) in a simple way. The only restricted values is the set electromagnetic torque (control signal). In such systems the only way to limit the amplitude of internal state variables is weakening the dynamics of the whole system. Another approach which allows to introduce the value restrictions of a selected state variable is using the cascade control structure in which a separate, subordinate control loop is formed. Then it is possible to restrict such state variable [16]. One of the methods allowing to introduce the restrictions of the values of state variables is predictive control. This method allows to introduce limitations as early as the controller design stage $[6,15]$.

The goal of this work is a comparison of various methods of restricting the amplitude of selected state variables of a drive with an elastic coupling and their influences on the dynamic properties of a drive. The comparison will encompass three control systems: the first one will use a classical PI controller with two additional feedbacks from selected state variables. The second investigated system will be a predictive speed controller calculated using multiparametric programming. The last, third, of the discussed solutions will be the cascade control structure based on the Force Dynamic Control.

(*) Tekst artykułu w polskiej wersji językowej dostępny w elektronicznym wydaniu kwartalnika na stronie www.ein.org.pl 


\section{Drive model}

A few models are used to describe a drive with an elastic coupling (a two-mass model), however, in the synthesis of the control system most frequently a model with an inertialess elastic coupling is used [17] written in relative units:

\section{Analysed control structures}

The drive structure is presented in Fig. 1.

The system is comprised of the discussed controller which sets the specified value of the electromagnetic torque on the basis of the estimated values of state variables. Next the value of this torque is

$$
\begin{aligned}
& \frac{d}{d t} \omega_{1}=\frac{1}{T_{1}}\left(m_{e}-m_{s}\right) \\
& \frac{d}{d t} \omega_{2}=\frac{1}{T_{2}}\left(m_{s}-m_{L}\right) \\
& \frac{d}{d t} m_{s}=\frac{1}{T_{c}}\left(\omega_{1}-\omega_{2}\right)
\end{aligned}
$$

where: $w_{1}, w_{2}$ - speed of the drive and machinery, $m_{e}, m_{s}, m_{L}-$ electromagnetic torque, torsional and loading, $T_{1}, T_{2}-$ mechanical time constant of the drive and machinery, $T_{c}$ - elasticity time constant. The above time constants can be determined on the basis of mechanical parameters and base units:

$$
T_{1}=\frac{\Omega_{b} J_{1}}{M_{b}} ; T_{2}=\frac{\Omega_{b} J_{2}}{M_{b}} ; T_{c}=\frac{M_{b}}{\Omega_{b} K_{c}}
$$

where: $J_{1}, J_{2}$ - moments of inertia related to the drive and machinery, $\Omega_{b}$ - reference pulsation, $M_{b}$ - reference electromagnetic torque, $K_{c}$ - elasticity constant.

Characteristic frequency parameters can be determined for the model described with equations (1a-c):

$$
\begin{gathered}
f_{r}=\frac{1}{2 \pi} \sqrt{T_{c} \frac{T_{1}+T_{2}}{T_{1} T_{2}}} \\
f_{a r}=\frac{1}{2 \pi} \sqrt{\frac{T_{c}}{T_{2}}}
\end{gathered}
$$

where: $f_{r}$ - resonance frequency of the mechanical system, $f_{a r}-$ antiresonance frequency of the mechanical system.

The value of the limitation of the torsional torque which can be safely transferred through the elastic clutch results from the properties used for its production. The value is usually bigger than the value resulting from the limitation:

$$
m_{s}^{\lim } \leq \frac{T_{2}}{T_{1}+T_{2}} m_{e}^{\lim }
$$

According to equation (4) the occurrence of the electromagnetic reserve allowing to attenuate the torsional torque in the system, the ratio of these torques must be at least equal to the ratio of the sum of mechanical time constants and $T_{1}$ and $T_{2}$ of both machines to time constant $T_{2}$. The values of the parameters of the analysed system were $\left(T_{I}=203 \mathrm{~ms}, T_{2}=203 \mathrm{~ms}, T_{c}=1.2 \mathrm{~ms}\right)$.

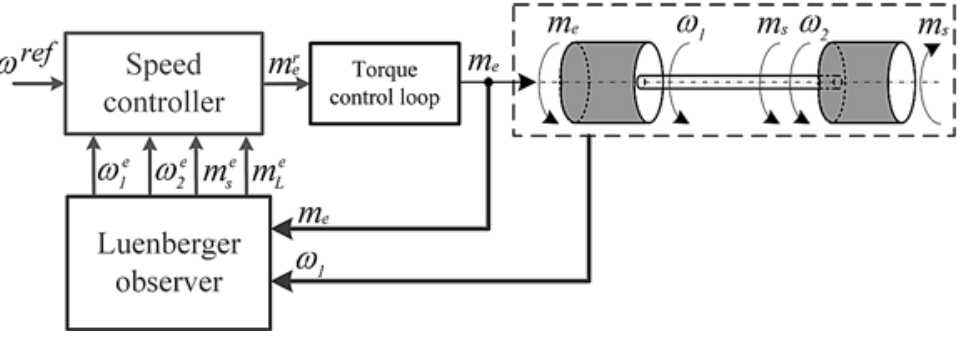

Fig. 1. General control structure.

shaped by the subordinate control system. The delay of this loop can be approximated using the first order inertia element with the time constant of $1 \mathrm{~ms}$.

In this work the Luenberger observer was used as the observer of state variables. The methodology of its design can be found in [19].

\subsection{PI regulator with two additional feedbacks}

One of the classical control structures is the PI controller with two additional feedbacks (from the torsional torque and the speed difference between the drive and the machinery) [17]. The proposed controller structure is presented in Fig. 2. It ensures the random distribution of poles on the complex plane, which allows for the extensive shaping of the closed system dynamics.

To determine the controller setting and the feedback coefficient, it is necessary to compare the conductive transmittance of the system with the reference transmittance [17]. The conductive transmittance of the closed system takes the following form:

$$
G=\frac{G_{R}}{s^{3} T_{1} T_{2} T_{c}+s^{2} T_{2}\left(G_{R} T_{c}\left(1+k_{8}\right)\right)+s\left(T_{1}+T_{2}\left(1+k_{1}\right)\right)+G_{R}}
$$

where:

$$
G_{R}=\frac{K_{I}}{s}+K_{p}
$$

After the substitution of (6) to (5) a polynomial characteristic for the discussed fourth order model is obtained.

According to the theory of modal control, to determine the controller settings and feedbacks, the obtained characteristic polynomial must be compared with the reference polynomial of the same order:

$$
\left(s^{2}+2 s \xi_{o} \omega_{0 o}+\omega_{0 o}^{2}\right)\left(s^{2}+2 s \xi_{o} \omega_{0 o}+\omega_{0 o}^{2}\right)
$$

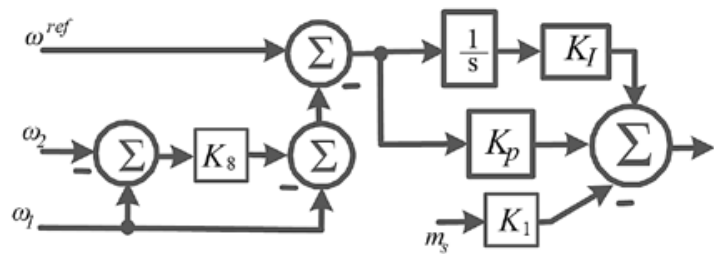

Fig. 2. Structure of the PI controller with two additional feedbacks. 
where: $\xi_{o}$ - attenuation coefficient, $\omega_{0 o}$ - resonance pulsation.

The comparison of the coefficients of particular orders allows to obtain expressions describing the reinforcement of the automatic control system:

$$
\begin{aligned}
& k_{8}=\frac{1}{\omega_{0 o}^{2} T_{2} T_{C}}-1 ; k_{1}=\frac{T_{1}\left(4 \xi_{o}{ }^{2}-k_{8}\right)}{T_{2}\left(1+k_{8}\right)} \\
& K_{I}=\omega_{0 o}^{4} T_{1} T_{2} T_{C} ; K_{P}=4 \xi_{o} \omega_{0 o}^{3} T_{1} T_{2} T_{C}
\end{aligned}
$$

The above dependencies allow to select reinforcement coefficients in the analysed control system.

\subsection{Cascade control structure based on the FDC law}

To enable the introduction of the limitations of state variables in the classical control structure based on the linear control theory one should use the cascade structure. In such a structure an internal control loop is made to take control of the state variable interesting for the authors and the limitation is introduced to the set value of the superior loop. In the case investigated in this work the limited variable is the torsional torque. The controller synthesis was conducted using the $F D C$ law.

The control was directly determined using drive model equation (1). The controlled variable must be differentiated so many times that the following control value is obtained in the equation:

$m_{s} \rightarrow \frac{d}{d t} m_{s}=\frac{1}{T_{c}}\left(\omega_{1}-\omega_{2}\right) \rightarrow \frac{d^{2}}{d t^{2}} m_{s}=\frac{1}{T_{c}}\left(\frac{1}{T_{1}}\left(m_{e}-m_{s}\right)-\frac{1}{T_{2}}\left(m_{s}-m_{L}\right)\right)$

The next step is the extraction of the control signal from the previous equation:

$$
\frac{d}{d t} m_{s}=\frac{1}{T_{c}}\left(\omega_{1}-\omega_{2}\right)
$$

Finally, the control law can be written in a simplified form:

$$
m_{e}=K_{1}\left(m_{s}^{r e f}-m_{s}\right)+K_{2} g_{1}\left(\omega_{1}-\omega_{2}\right)+K_{3} m_{s}+K_{4} m_{L}
$$

Where:

$K_{1}=\omega_{r m s} T_{1} T_{c} ; \quad K_{2}=-2 \xi_{m s} \omega_{r m s} T_{c} T_{1} ; \quad K_{3}=\frac{T_{1}+T_{2}}{T_{2}} ; K_{4}=-\frac{T_{1}}{T_{2}} ; g_{1}=\frac{1}{T_{c}}$

A controller was used in the speed control loop to make it possible to control the machinery speed, its control law was derived analogically to the previous subsection:

$$
\begin{gathered}
\frac{d}{d t} \omega_{2}=\frac{1}{T_{2}}\left(m_{s}-m_{L}\right) \\
G_{r e f}=\frac{\omega_{2}}{\omega^{r e f}}=\frac{1}{\frac{d}{d t} T_{z}+1}
\end{gathered}
$$

$$
m_{s}^{r e f}=\frac{T_{2}}{T_{z}}\left(\omega_{r e f}-\omega_{2}\right)+m_{L}
$$

The regulator structure is presented in Fig. 3.

$\frac{1}{T_{c} T_{1}} m_{e}=\frac{d^{2}}{d t^{2}} m_{s}+\frac{1}{T_{c} T_{1}} m_{s}+\frac{1}{T_{c} T_{2}} m_{s}-\frac{1}{T_{c} T_{2}} m_{L}$

Because in equation (10) there is the second power of the differential operator, the adopted reference model is the second order system:

$$
G_{r e f}=\frac{m_{s}}{m_{s}^{r e f}}=\frac{\omega_{r}^{2}}{\frac{d^{2}}{d t^{2}}+\omega_{r m s} \xi_{m s} \frac{d}{d t}+\omega_{r m s}^{2}}
$$

After the determination of the second derivative of the controlled variable from equation (11) and substituting it to equation (10), after ordering, the control law is obtained:

$m_{e}=\omega_{r} T_{c} T_{1}\left(m_{s}^{r e f}-m_{s}\right)+\left(-2 \xi_{m s} \omega_{r m s} T_{c} T_{1}\right) \frac{d}{d t} m_{s}+\left(1+\frac{T_{1}}{T_{2}}\right) m_{s}+\left(-\frac{T_{1}}{T_{2}}\right) m_{L}$

Where: $\omega_{\text {rms }}-$ model resonance pulsation, $\xi_{m s}-$ attenuation coefficient. With the use of equation (1), it is possible to determine the controlled variable derivative:

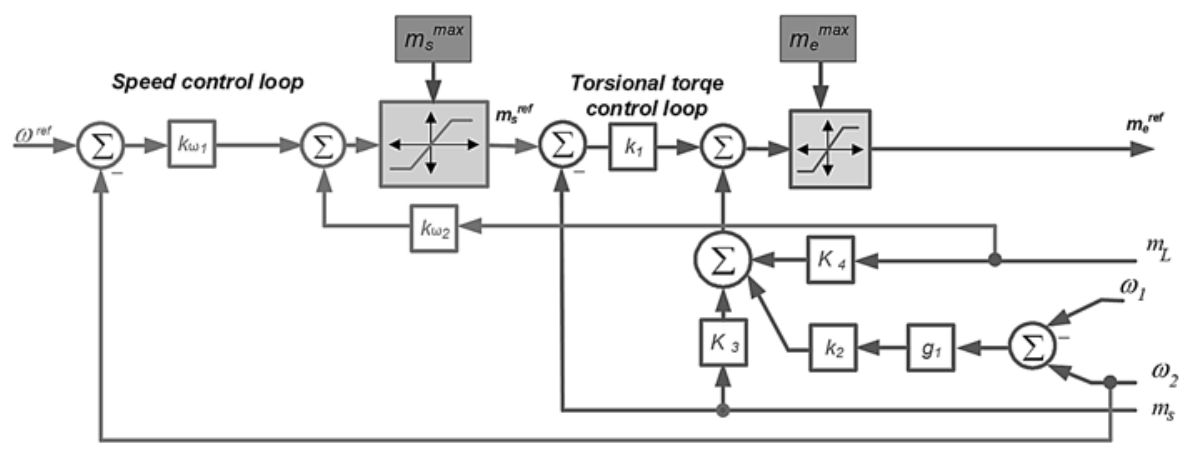

Fig. 3. Structure of the cascade regulator based on the FDC law.

\subsection{Predictive controller with the state space model}

The strategy of predictive control is the determination of control sequences whose number depends on the control horizon minimising the set objective function over the prediction horizon of outputs. The values of the future actions of an object are determined on the basis of the model. For this purpose the two-mass model (1) was extended by three additional variables: load torque, reference speed and the dynamics of torque enforcement loop. In the case of the first two values, their dynamics is unknown.

$$
\frac{d}{d t} m_{L}=0 \quad \frac{d}{d t} \omega^{r e f}=0
$$


Finally the drive state vector consists of six elements:

$$
X_{c}=\left[\begin{array}{lllll}
\omega_{1} & \omega_{2} & m_{s} & m_{L} & \omega^{r e f}
\end{array}\right]^{T}
$$

The model described by equation (1) taking into account (18) and the defined state vector (19) is presented in equation (20). Next the above model was discreticised with sampling time $T_{s}$ using the Euler method.

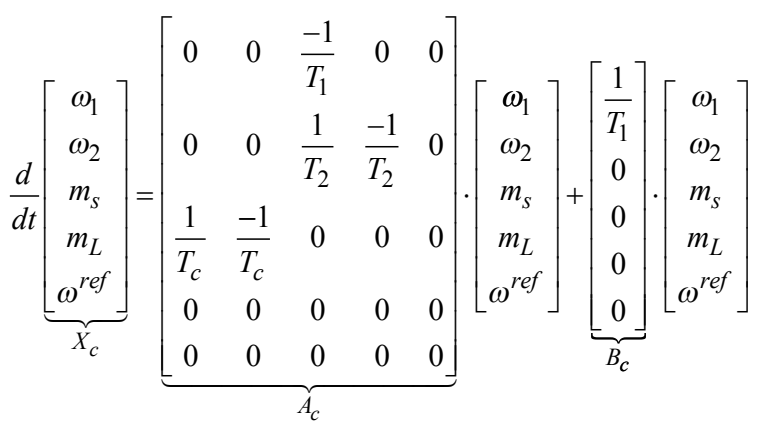

where: $\omega_{1}-$ drive speed, $\omega_{1}-$ machinery speed, $\omega^{\text {ref }}-$ set speed, $m_{s}-$ torsional torque, $m_{L}-$ load torque.

For the purpose of preventing the drive from damage, the limitation of the electromagnetic and torsional torque was introduced:

$$
\begin{aligned}
& -3 \leq m_{e} \leq 3 \\
& -1.5 \leq m_{s} \leq 1.5
\end{aligned}
$$

In the case of two-mass drives, the minimised outputs are:

$$
\begin{aligned}
& y_{1}=\omega_{1}-\omega^{r e f} \\
& y_{2}=\omega_{2}-\omega^{r e f} \\
& y_{3}=m_{s}-m_{L}
\end{aligned}
$$

The first and the second outputs are responsible for the minimisation of the difference between the speed of the drive and the load, and the set speed. The third output is responsible for the minimisation of the difference between the torsional torque an the load. In summary, the determination of controls can be described by the following dependencies:

$$
\begin{gathered}
\min _{u_{1}, u_{2}, \cdots, u_{N c}-1} \sum_{k=0}^{N}\left(q_{1}\left(y_{1}(k)\right)^{2}+q_{2}\left(y_{2}(k)\right)^{2}+q_{3}\left(y_{3}(k)\right)^{2}\right)+\sum_{j=1}^{N c-1} r\left(m_{e}(j)\right)^{2} \\
\left|m_{e}\right| \leq 3 \\
\left|m_{s}\right| \leq 1.5
\end{gathered}
$$

where: $q_{1} \ldots q_{4}$ - weights differentiating the influence of particular outputs on the control value, $r$ - weight influencing control attenuation, $N$ - output prediction horizon, $N_{c}-$ control prediction horizon, $m_{e}-$ electromagnetic torque.

The predictive control algorithm can be implemented in two ways. The traditional way encompasses solving the on-line optimisation problem for a given state of system $x(k)$ and the adopted length of the prediction horizon in the algorithm. It should be emphasised here that an increase in the length of the prediction period allows to obtain better dynamic properties of the object, however, it also significantly influences the complexity of the control algorithm (increases the required computational effort). In practice, very frequently the constant value of the control signal is assumed for the whole prediction horizon. This significantly reduces the computational complexity of the whole algorithm. After the determination of the optimum value of the control signal at instant $k$, it is transferred to the controlled object. The next computational instant $(k+1)$ the whole procedure is repeated with account for the current values of the state vector of object $x(k+1)$ (measured or estimated). The described control strategy requires the use of fast microprocessor systems and this is why it used in the case of objects with relatively high time constants.

In the other method the problem of the optimisation of a given form of objective function (23) is solved off-line for all combinations of state vector $x \hat{I} X_{f}$ with the use of multiparametric programming $[1,11]$. It allows to demonstrate that space $X_{f}$ can be divided into the regions in which the optimiser is expressed as an explicit function for the set values of vector $x$. The control law can be treated one-piece continuous and expressed as follows:

$$
U(x)=\mathbf{K}_{\mathbf{r}} \mathbf{x}+g_{r}, \quad \forall \mathbf{x} \in P_{r}
$$

where $P_{r}$ are polyhedral sets defined as:

$$
P_{r}=\left\{x \in \mathfrak{R}^{n} \mid H_{r} x \leq d_{r}\right\} \quad r=1, \ldots N_{r}
$$

The design algorithms of polyhedral sets and the control law computations are described in detail in $[20,21]$. In the simplest case the control law can be calculated by searching all regions one after another until the active one is found and subsequent implementation of the control law in accordance with (23). It should be noted that in the primary sources it is possible to find more effective algorithms of the generation of the control law current value. The substitution of the online optimisation with its off-line version allows to put to practice predictive control in systems with small time constants, such as electrical drives. The direct comparison of these solutions is presented in [5].

\section{Simulation research}

This section presents the selected comparative results showing the operation of the investigated control structures. The research was conducted in the Matlab/Simulink environment. Controller parameters were selected in such a way that they ensured approximate dynamic properties (setting time and resetting). Controller parameters with the so selected criteria are presented in Table1.

The drive operated in the following cycle: first it was started and reached the set speed, next at time $\mathrm{t}=0.5 \mathrm{~s}$ the rated load torque was applied. First of all the operation of the PI controller with additional feedbacks was investigated. For the purpose of these considerations three values of the set speed were adopted: 0.25 , the rated value and the value when the ramp of set speed changes was used. The obtained results are presented in Fig. 4.

In the case of drive operation with the $P I$ controller, in the low set speed zone the controller managed to efficiently attenuate the me-

Table 1. Parameters of the investigated control structures

\begin{tabular}{||c|c|c|c|c||}
\hline \multirow{2}{*}{ Reg } & \multirow{2}{*}{ PI } & \multicolumn{2}{|c||}{ FDC } & \multirow{2}{*}{ MPC } \\
\cline { 3 - 4 } & FDC- $\mathrm{m}_{\mathrm{s}}$ & FDC- $\omega_{2}$ & \\
\hline Parameters & $\omega_{r}=90 \mathrm{rad} / \mathrm{s} ; \zeta=0.95$ & $\omega_{\mathrm{rms}}=180 \mathrm{rad} / \mathrm{s} ; \zeta_{m s}=0.7$ & $T_{z}=0.035 \mathrm{~s}$ & $\begin{array}{l}q_{1}=50 ; q_{2}=1 ; q_{3}=65 ; \\
r=1 \mathrm{e}-3 ; N=10 ; N_{c}=2\end{array}$ \\
\hline
\end{tabular}



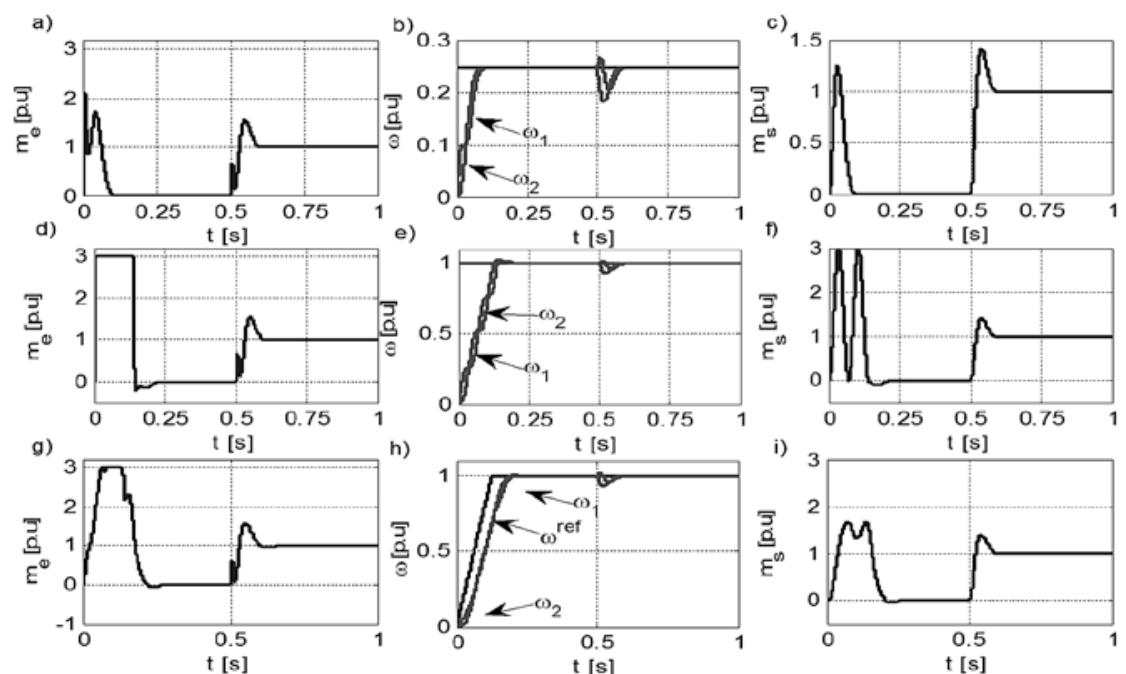

Fig. 4. Transients in the system with the PI controller for three set values: $0.25(a, b, c)$, rated value $(d, e, f)$ and speed changes after leaving a ramp $(g, h, i)$, where $a), d), g)$ electromagnetic torque, b),e),h) speed transients, c),f),i) torsional torque transients
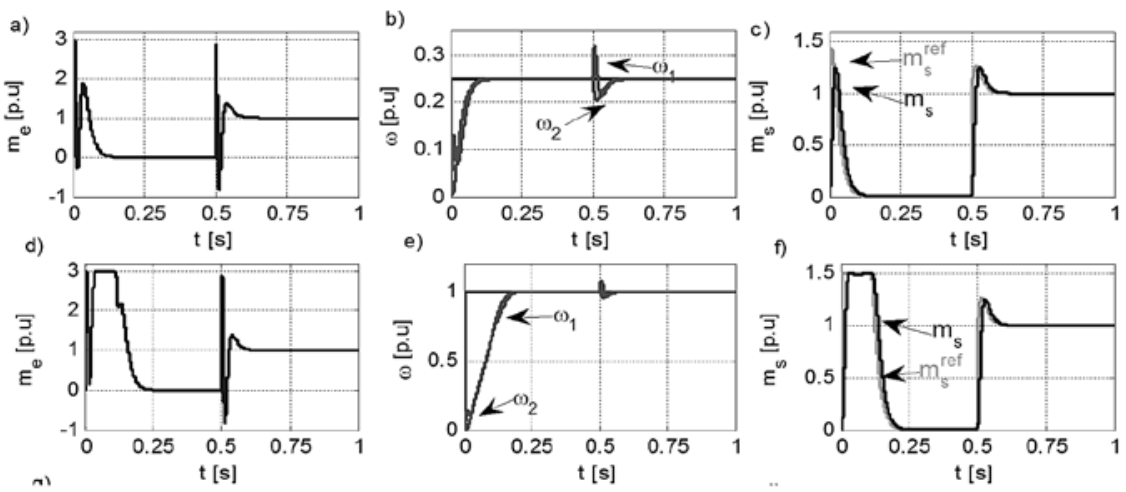

Fig. 5. Transients in the system with the FDC controller for two set values: $0.25(a, b, c)$ rated value $(d, e, f)$, where a), d), g) electromagnetic torque, $b), e), h)$ speed transients, $c), f), i)$ torsional torque transients
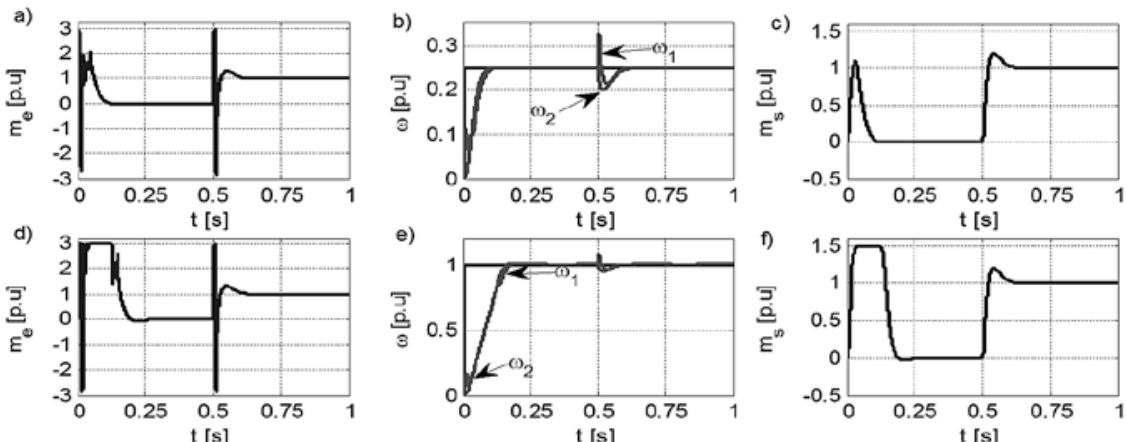

Fig. 6. Transients in the system with the MPC controller for two set values: $0.25(a, b, c)$ and rated value $(d, e, f)$, where a),d),g) electromagnetic torque, b),e),h) speed transients, $c), f), i)$ torsional torque transients

Table 2. Values of ITAE quality criterion of the tested control systems (values $\times 10^{-3}$ )

\begin{tabular}{|c|c|c|c|c|c|c|c|c|c|c|}
\hline \multirow{2}{*}{} & \multicolumn{5}{|c|}{$\omega^{\text {ref }}=0.25$} & \multicolumn{5}{c|}{$\omega^{\text {ref }}=1$} \\
\cline { 2 - 12 } & Nom. & $2 \mathrm{~T}_{\mathrm{cn}}$ & $0.5 \mathrm{~T}_{\mathrm{cn}}$ & $2 \mathrm{~T}_{2 \mathrm{n}}$ & $0.5 \mathrm{~T}_{2 \mathrm{n}}$ & Nom. & $2 \mathrm{~T}_{\mathrm{cn}}$ & $0.5 \mathrm{~T}_{\mathrm{cn}}$ & $2 \mathrm{~T}_{2 \mathrm{n}}$ & $0.5 \mathrm{~T}_{2 \mathrm{n}}$ \\
\hline PI & 0.17 & 0.91 & 0.13 & 5.13 & 0.058 & 8.82 & 7.53 & 7.41 & 14.9 & 2.90 \\
\hline FDC & 0.12 & 0.19 & 0.38 & 0.43 & 0.042 & 2.16 & 2.64 & 3.09 & 8.17 & 1.08 \\
\hline MPC & 0.10 & 0.28 & 0.08 & 0.26 & 0.075 & 2.10 & 2.80 & 3.30 & 7.55 & 1.13 \\
\hline
\end{tabular}

chanical oscillations of state variables. However, at the set rated speed when the controller reaches the electromagnetic torque limitation, the oscillation attenuation properties deteriorate and the values of torsional torque limitations are violently exceeded (Fig. 4.f). One of the ways of solving this problem is the use of a ramp after which there is a change of the set speed (Fig. 4.h). In this case after the appropriate selection of the ramp slope, it is possible to limit the amplitude of the torsional torque. However, it should be noted that this approach deteriorates the drive dynamics.

Next the power transmission system with the FDC cascade controller structure was tested. The obtained results are presented in Fig. 5. It can be observed that the set speed is reached in both cases without exceeding the limitation of the torsional torque with simultaneous complete attenuation of torsional vibration. In the case of the investigated structure there was no necessity to introduce additional ramps along the set speed path.

The last of the tested systems was the predictive controller. The transients of selected state variables are presented in Fig. 6. It can be observed that the predictive controller allows for the quick reaction of speed with simultaneous torsional vibration attenuation and the limitation of the torsional torque amplitude.

Because the figures presented above do not clearly show the influence of the applied load torque, Fig. 7 shows the comparison of state variable transients when the load is applied.

The presented transients allow to observe that the FDC controller ensures the smallest deviation in the load speed control (Fig. 7d), which results from the introduction of the estimated load value at the torque control node. The predictive controller ensures very similar properties regardless of the lack of the torsional torque controller. In the group of the compared structures the PI controller has the weakest dynamic properties although it is tuned to the resonance frequency of $90 \mathrm{rad} / \mathrm{s}$.

To compare the operation of the investigated structures, they underwent comparative research using the ITAE criterion.

$$
J=\underbrace{\int_{t=0}^{t_{1}}\left(t \cdot\left|\omega^{r e f}-\omega_{2}\right|\right) d t}_{\text {ITAE }\left(\omega_{2}\right)}+\underbrace{\int_{t t_{1}}^{t_{2}}\left(t \cdot\left|\omega^{r e f}-\omega_{2}\right|\right) d t}_{I T A E\left(m_{l}\right)}
$$

The tests were conducted for 0.25 of the rated value and nominal speed. Additionally it was tested this value is influenced by the change of drive mechanical parameters $\left(T_{c}\right.$ and $\left.T_{2}\right)$. The results obtained for selected values are presented in Table 2 . To improve the readability of the values presented in the table, the indicator values is multiplied by $10^{-3}$. Fig. 8 presents the value changes of indicator $J$ as a function of parameter change.

The presented results show that when the mechanical parameters of the drive are changed, the predictive controller preserves the best properties. 

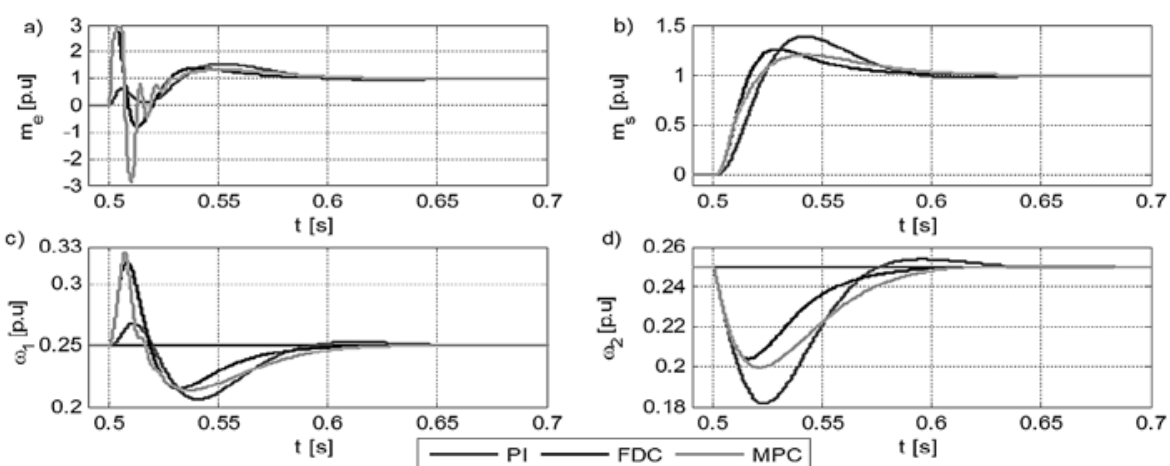

Fig. 7. Comparison of the impact of the described structures on the application of load torque: a) electromagnetic torque, b) torsional torque, c) drive speed, d) load speed
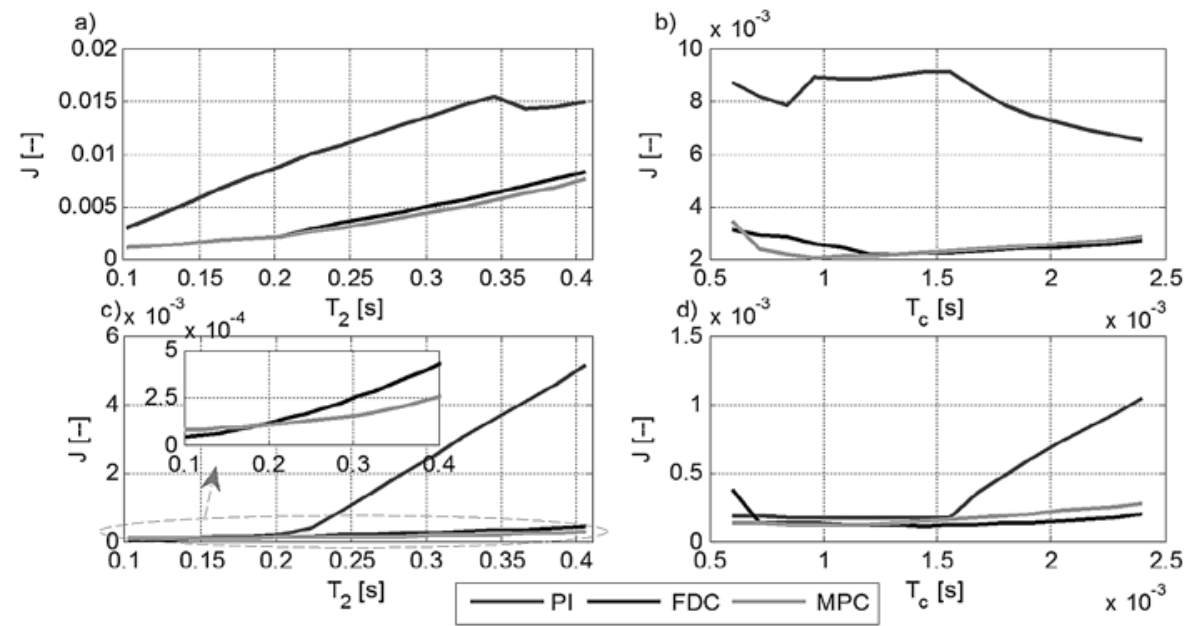

Fig. 8. Influence of mechanical parameters $T_{2}(a, c)$ and $T c(b, d)$ on the value of the ITAE indicator at: $\left.a\right)$ b), set rated value, c),d) 0.25 speed

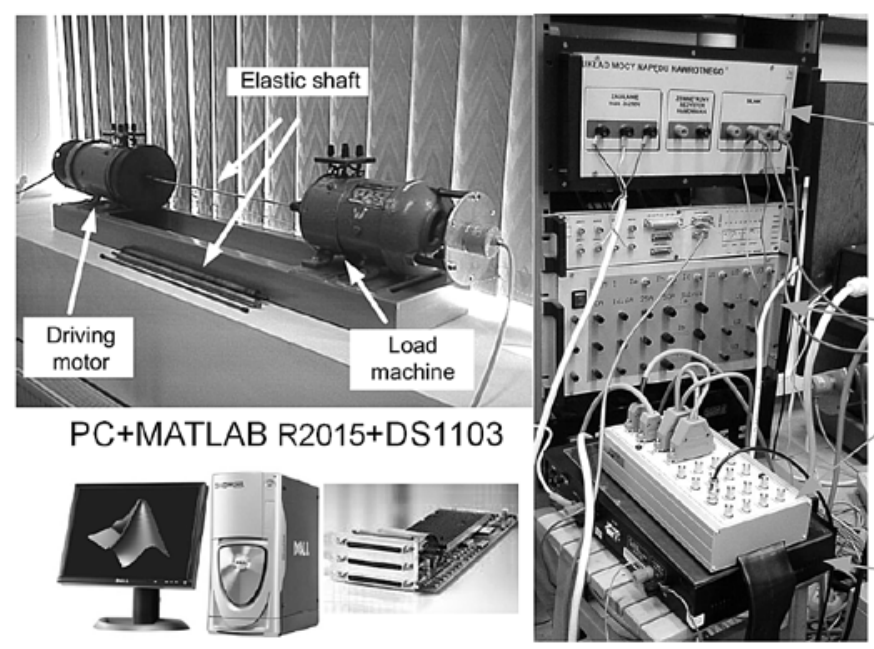

Fig. 9 Experimental set-up

In the case of the $F D C$ controller, the results are similar, however, when the parameters are incorrectly identified state variables oscillations appear in the system. The transients presented in Fig. 8 show that the dynamic properties of the $P I$ regulator are the weakest in the whole range of parameter change. In the case of $F D C$ it can be observed that it has better dynamic properties than the predictive controller for values smaller than the rated one (Fig. 8b,c).

\section{Experimental research}

The experimental research was conducted at an experimental set-up made of $500 \mathrm{~W}$ DC motors connected with a long shaft. The driving motor was fed by a power converter operating in the H-bridge configuration. The bridge was controlled by a hardware pulse-width modulator, carrier frequency $10 \mathrm{kHz}$. The speed of the driving motor was measured with an incremental encoder, resolution 36000 pulses per revolution. The current was measured with a halotronic converter made by $L E M$. The algorithm was implemented on the DS1103 card with a signal processor. To ensure the optimum operation of the whole control structure, the control circuit of the electromagnetic torque, working with the PI controller, was calculated with a frequency of $10 \mathrm{kHz}$. The discussed controllers and observer worked at a step size of $1 \mathrm{~ms}$. Fig. 9 presents the view of the described experimental set-up.

During the research the driving motor was cyclically started using the investigated control structures. In these considerations the $P I$ controller with a ramp as well as the $M P C$ and $F D C$ controllers were adopted. The obtained results are presented in Fig. 10.

The emphasise time differences in speed determination, the results presentation time was reduced to $0.5 \mathrm{~s}$. It can be seen that reply was provided by the predictive controller which can also effectively limit the amplitude of the torsional torque (Fig.10c,d). In the case of the PI controller, the increasing speed determination time can be clearly observed (Fig. 10a,b).

In the case of a start-up with the FDC controller, some problems with the efficient estimation of the torsional torque occurred in the physical system, which resulted in the necessity to limit the resonance frequency set up in the internal controller of torsional torque to the value $\omega_{r m s}=140 \mathrm{rad} / \mathrm{s}$. This tuning allowed the system to operate correctly, however, a significant level of noise could be observed in torsional torque transients (Fig. 10.e).

Fig. 11 presents transients obtained in the system with the PI controller with the use of a ramp.

It can be observed that big amplitudes of torsional torque and speed oscillations occur in the system.

dSPACE

connector

panel

brake

system

\section{Summary}

The article presents a comparison of three drive control structures with an elastic coupling taking into account the possibility of limiting the torsional torque. It also includes the abridged methodology of the design of the discussed

a)
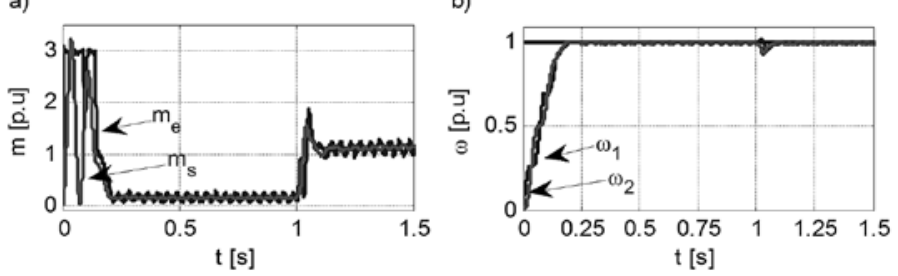

Fig. 10. Experimental transients of state variables for the regulator: PI $(a, b), M P C$ $(c, d), F D C(e, f)$, where a),c),e) torque transients, b),d),f) speed transients 
a)

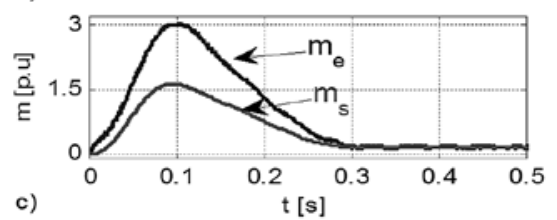

c)
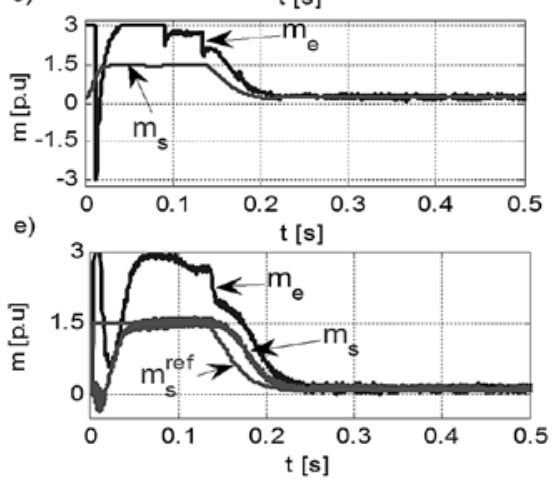

b)

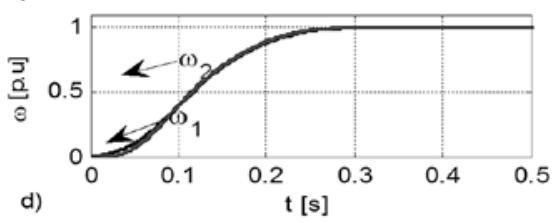

d)
$\stackrel{\Xi}{3} 0.5$
f)
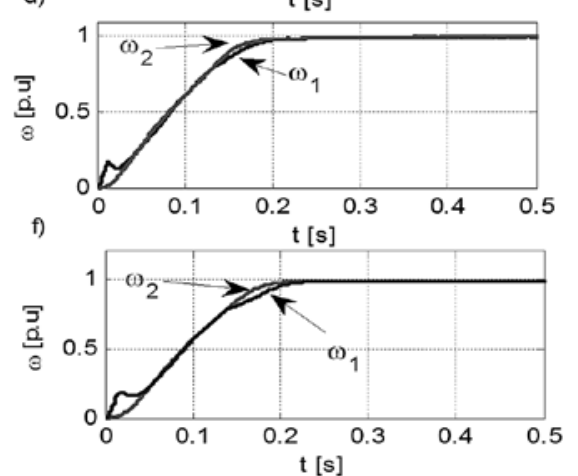

structures as well as the simulation experimental results. The presented considerations lead to the following results:

- used methods allow to efficiently attenuate torsional vibration.

- application of advanced control structures allow to efficiently limit the torsional torque amplitude and, hence, increase the life of clutches and shafts. - in the case of the cascade FDC structure, problems with the estimation speed of torsional torque occurred which was reflected in the quality of operation.

Fig. 11. Transients in the system with the PI controller without a ramp: a) torques, b) speeds

\section{References}

1. Bemporad A., Morari M., Dua V., Pistikopoulos E.N., The explicit linear quadratic regulator for constrained systems, Automatica 2002; 38 (1): 3-20, https://doi.org/10.1016/S0005-1098(01)00174-1.

2. Boukhezzar B., Siguerdidjane H., Comparison between linear and nonlinear control strategies for variable speed wind turbines, Control Engineering. Prac. 2010; 18(12): 1357-1368.

3. Brock S., Luczak D., Nowopolski K., Pajchrowski T., Zawirski K., Two Approaches to Speed Control for Multi-Mass System with Variable Mechanical Parameters, IEEE Trans. on Industrial Electronics 2016; early accepted.

4. Chang Y.C., Yen H.M., Design of a robust position feedback tracking controller for flexible-joint robots, IET Control Theory and Applic. 2011; 5(2): 351-363, https://doi.org/10.1049/iet-cta.2010.0166.

5. Cychowski M., Szabat K., Efficient real-time model predictive control of the drive system with elastic transmission, IET Control Theory \& Applic. 2010; 4(1): 37-49, https://doi.org/10.1049/iet-cta.2008.0358.

6. Cychowski M., Szabat K., Orlowska-Kowalska T., Constrained Model Predictive Control of the Drive System With Mechanical Elasticity, IEEE Trans. on Industrial Electronics 2009; 56(6): 1963-1973, https://doi.org/10.1109/TIE.2009.2015753.

7. Derugo, P., Szabat, K., Adaptive neuro-fuzzy PID controller for nonlinear drive system, COMPEL: The International Journal for Computation and Mathematics in Electrical and Electronic Engineering 2015; 34(3): 792 - 807, https://doi.org/10.1108/COMPEL-10-2014-0257.

8. Dróżdż K. Adaptive control of the drive system with elastic coupling using fuzzy Kalman filter with dynamic adaptation of selected coefficients. Eksploatacja i Niezawodnosc - Maintenance and Reliability 2015; 17 (4): 561-568, http://dx.doi.org/10.17531/ein.2015.4.11.

9. Erenturk K., Nonlinear two-mass system control with sliding-mode and optimised proportional-integral derivative controller combined with a grey estimator, IET Control Theory \& Applic. 2008; 2(7): 635-642, https://doi.org/10.1049/iet-cta:20070330.

10. Karolewski B., Ligocki P., Modelling of long belt conveyors, Eksploatacja i Niezawodnosc - Maintenance and Reliability 2014; 16(2): 179-187.

11. Kvasnica M., Grieder P., Baotic M., Morari M., Multi-Parametric Toolbox (MPT), HSCC (Hybrid Systems: Computation and Control), Lecture Notes in Computer Science 2004; 2993: 448-465, https://doi.org/10.1007/978-3-540-24743-2_30.

12. Montague R., Bingham C., Atallah K., Servo Control of Magnetic Gears, IEEE/ASME Transactions on Mechatronics 2012; 17(2): 269-278, https://doi.org/10.1109/TMECH.2010.2096473.

13. Preitl S., Precup R-E., Stînean A-I., Dragos C-A., Radac M-B., Control structures for variable inertia output coupled drives, 2012 4th IEEE International Symposium on Logistics and Industrial Informatics, https://doi.org/10.1109/lindi.2012.6319484.

14. Schuster H., Hackl C., Westermaier C., Schroder D., Funnel-control for electrical drives with uncertain parameters, The 7th International Power Engineering Conference, (IPEC), Singapore 2005; 516-522

15. Serkies P., Szabat K., Application of the MPC controller to the Position Control of the Two-Mass Drive System, IEEE Trans. on Industrial Electr. 2013; 60(9): 3679 - 3688, https://doi.org/10.1109/TIE.2012.2208435.

16. Serkies P., Szabat K., Dodds S., Cascade speed control structure with limited of torsional torque based on the FDC method in two-mass drive, IECON 201541 st Annual Conference of the IEEE Industrial Electronics Society: November 9-12, 2015, Yokohama, Japan. [Piscataway, NJ]: IEEE, cop. 2015: 3969-3973.

17. Szabat K., Orlowska-Kowalska T., Vibration Suppression in a Two-Mass Drive System Using PI Speed Controller and Additional FeedbacksComparative Study, IEEE Trans. on Industrial Electronics 2007; 54(2): 1193-1206, https://doi.org/10.1109/TIE.2007.892608.

18. Szabat K., Orłowska-Kowalska T., Application of the Kalman Filters to the High-Performance Drive System With Elastic Coupling, IEEE Trans. on Industrial Electronics 2012; 59(11): 426-4235, https://doi.org/10.1109/TIE.2012.2183836.

19. Szabat K., Tran-Van T., Kamiński M., A Modified Fuzzy Luenberger Observer for a Two-Mass Drive System, IEEE Trans. on Industrial Informatics 2015; 11(2): 531 - 539, https://doi.org/10.1109/TII.2014.2327912.

20. Valenzuela M. A., Bentley J. M., Lorenz R. D., Computer-Aided Controller Setting Procedure for Paper Machine Drive Systems, IEEE Trans. on Industrial Electronics 2009; 45(2): 638-650, https://doi.org/10.1109/tia.2009.2013588. 
21. Vasak M., Baotic M., Petrovic I., Peric N., Hybrid Theory-Based Time-Optimal Control of an Electronic Throttle, IEEE Trans. on Industrial Electronics 2007; 54(3): 1483- 1494, https://doi.org/10.1109/TIE.2007.893060.

22. Zhang G., Furusho J., Speed control of two-inertia system by PI/PID control, IEEE Trans. on Industrial Electronics 2000;. 47(3): 603-609, https://doi.org/10.1109/41.847901.

\section{Piotr SERKIES}

Department of Electric Machines, Drives and Measurements

Wrocław University of Science and Technology

Wyb. Wyspiańskiego 27, 50-370 Wrocław, Poland

E-mail: piotr.serkies@pwr.edu.pl 